\title{
An indel polymorphism in the 3 ' untranslated region of HMGB 1 confers risk for hepatocellular carcinoma by regulating HMGB1 transcriptional activity in a Chinese population
}

\author{
J. WANG1, J. ZHU2, D. H. MAO ${ }^{3}$, S. ZHU ${ }^{4}$, X. G. MI', Q. YU \\ ${ }^{1}$ Department of Medical Oncology, The Fifth People's Hospital of Changshu, Changshu, Jiangsu, 215500, China; ${ }^{2}$ Department of Gastroenterol- \\ ogy, JingJiang People's Hospital, Jingjiang, Jiangsu, 214500, China; ${ }^{3}$ General Surgery, ${ }^{4}$ Gastroenterology and ${ }^{5}$ General Internal Medicine, The \\ Fifth People's Hospital of Changshu, Changshu, Jiangsu, 215500, China; ${ }^{6}$ Department of Gastroenterology, Suzhou Municipal Hospital, The \\ Affiliated Suzhou Hospital of Nanjing Medical University, Suzhou, Jiangsu 215002, China
}

${ }^{*}$ Correspondence: $24500265 @ q q . c o m$

Received February 21, 2019 / Accepted June 6, 2019

\begin{abstract}
The present study aimed to assess the association of rs34000982 polymorphism located in the 3' untranslated region (3' UTR) of high mobility group box 1 (HMGB1) gene and the risk of hepatocellular carcinoma (HCC), and further to explore the underlying mechanism. Genomic DNA was extracted from peripheral blood of 320 patients with HCC and 360 matched controls. Rs34000982 polymorphism was genotyped by a polymerase chain reaction-polyacrylamide gel electrophoresis assay. The genotype-phenotype association of HMGB1 mRNA and protein expression in HCC tissues with different genotypes was detected by quantitative (q) PCR assay and western blot. Vectors containing the insertion (ins)/ins or deletion (del)/del genotype of the rs34000982 polymorphism were constructed and the HMGB1 transcriptional activity affected by the rs34000982 polymorphism was detected by the luciferase assay. It was identified that the ins/ins genotype of rs34000982 significantly increased the risk of HCC compared with the del/del genotype. Further the qPCR results demonstrated that the HMGB1 mRNA expression level in HCC tissues with ins/ins genotype was 2.24 times that of HCC tissues with ins/del and del/del genotypes and there was a similar trend at protein level. In addition, the insertion allele of rs34000982 disturbed the binding of miR-636 with the 3' UTR of HMGB1, thereby increasing HMGB1 transcriptional activity in vitro. These data suggest that the rs 34000982 polymorphism may contribute to HCC susceptibility, in full or at least partially through the effect on HMGB1 transcriptional activity by disturbing the binding of miR-636 with the 3' UTR of HMGB1.
\end{abstract}

Key words: insertion/deletion polymorphism, rs34000982, high mobility group box 1, hepatocellular carcinoma

Liver cancer is the sixth most common cancer globally and the fourth most common cause of cancer-related deaths worldwide in 2018, with about 841,000 new cases and 782,000 deaths annually [1]. Hepatocellular carcinoma (HCC), characterized as an inflammation-related carcinoma, comprising $75-85 \%$ of primary liver cancer, whose main risk factors are Hepatitis B virus (HBV) infection and aflatoxincontaminated foodstuffs, especially in high risk areas including China [2], along with genetic factors also playing important roles in HCC [3]. Despite the intense study of HCC in previous years, the molecular mechanism remains incompletely characterized [4].

High-mobility group box 1 (HMGB1) is a highly conserved and widely expressed nuclear DNA binding protein $[5,6]$. Nuclear functions of HMGB1 are essential to life since HMGB1 knockout mice die within 24 hours of birth from hypoglycemia in cells [7]. Once released, extracellular HMGB1 binds to several cell surface receptors including receptor for advanced glycation end product (RAGE) [8, 9], the toll-like receptors [10-13] etc., to activate the downstream signaling pathway. Therefore, HMGB1 has enormous biological functions through interacting with the abovementioned receptors and serves as a key component in many diseases including cancers, such as breast cancer [14], tumors of the gastrointestinal tract $[15,16]$ and also hepatocellular carcinoma [17].

Because of the important roles of HMGB1 gene, its expression regulation is critical, and Muller et al. have summarized its expression regulation at different levels, especially at transcriptional level through different mechanisms [18].The 
3' untranslated region ( 3 ' UTR) is considered to be an area with abundant microRNA (miRNA) targets and participates in the regulation of gene expression. So genetic polymorphisms in the 3' UTR of genes may affect gene expression through creating new or disturbing the original miRNA bindings. Rs34000982 is a 4-bp indel polymorphism in the 3' UTR of $H M G B 1$, in the present study we analyzed the association between rs34000982 polymorphism and HCC susceptibility in a Chinese population, and the potential mechanisms through which the insertion-deletion (indel) polymorphism affects $H M G B 1$ expression.

\section{Materials and methods}

Study populations. Both cases and controls recruited were non-consanguineous ethnic Han Chinese individuals. All 320 HCC cases were diagnosed, hospitalized and treated in the Fifth People's Hospital of Changshu (Changshu, China) and Suzhou Municipal Hospital (Suzhou, China) between May 2010 and January 2017. None of the patients with HCC had been administered any medical treatment prior to providing peripheral blood samples. The diagnosis of the HCC cases, the exclusion and inclusion criteria for all the participants, and the definitions of smokers and drinkers were the same as described previously [19-21]. The diagnosis of these patients was confirmed by a pathological examination combined with positive imaging (magnetic resonance imaging and/or computerized tomography). The matched 360 cancer-free controls were selected during a routine physical examination conducted in the same regions during the same period as the recruitment of the HCC cases. All controls had no history of cancer, and were negative for antibodies to hepatitis $\mathrm{C}$ virus, hepatitis $\mathrm{D}$ virus, and human immunodeficiency virus. The 60 newly diagnosed and pathologically confirmed HCC tissues were collected following surgical resection without preoperative chemotherapy or radiotherapy. Tumor stages were determined using a modified American Joint Committee on Cancer and International Union Against Cancer system [22]. Written informed consents were gained from all the participants. The design of the study was approved by the Ethics Committee of the Fifth People's Hospital of Changshu (Changshu, China) and Suzhou Municipal Hospital (Suzhou, China).

DNA extraction and genotyping. Peripheral blood DNA was extracted using a DNeasy Blood \& Tissue kit (cat no. 69504; Qiagen GmbH, Hilden, Germany). DNA fragments containing the rs34000982 polymorphism were amplified using the following primers: 5'-AAGTAAATGGAAGTGGGAGGCAAT-3' (forward) and 5'-CCCACAGCACTGTAACTATCTTG-3' (reverse). The polymerase chain reaction (PCR) was performed in a total volume of $20 \mu \mathrm{l}$, containing $2.0 \mu \mathrm{l}$ 10X PCR buffer, $1.2 \mu \mathrm{l} 25 \mathrm{mM} \mathrm{MgCl} 2,1 \mu \mathrm{l} 10 \mathrm{mM}$ dNTP Mix, $1 \mu \mathrm{l} 10 \mathrm{mM}$ for each primer, $50 \mathrm{ng}$ genomic DNA, and 1.0 U Taq DNA polymerase (GenStar Biosolutions Co., Beijing, China). The amplification protocol consisted of an initial denaturation at $94^{\circ} \mathrm{C}$ for $2 \mathrm{~min}$, followed by 34 cycles of denaturation at $94^{\circ} \mathrm{C}$ for $30 \mathrm{~s}$, annealing at $58^{\circ} \mathrm{C}$ for $30 \mathrm{~s}$ and extension at $72^{\circ} \mathrm{C}$ for $45 \mathrm{~s}$, followed by a final extension at $72^{\circ} \mathrm{C}$ for $5 \mathrm{~min}$. A $7 \%$ non-denaturing polyacrylamide gel electrophoresis (PAGE) and silver staining method was used to analyze the PCR products [23]. The 4-base pair (bp) deletion/insertion (del/ins) allele of rs34000982 yielded bands of 117 and $121 \mathrm{bp}$, respectively. Genotyping was performed without knowledge of case or control status. The quality control was performed as follows: in order to validate the genotyping method, 15 randomly selected DNA samples were sequenced by Genewiz Inc. (South Plainfield, NJ, USA) following genotyping; to confirm $100 \%$ consistency, $\sim 10 \%$ of the total DNA samples were randomly selected for genotyping in duplicate by 2 independent technicians.

Quantitative (q)PCR analysis. Total RNA was extracted from 60 HCC tissue samples with different genotypes using an RNeasy Mini Kit (cat no. 74106; Qiagen) and reverse transcribed used the Superscript II reverse transcriptase (cat no. 18064-014; Invitrogen; Thermo Fisher Scientific, Inc., Waltham, MA, USA). Next, to quantify the relative mRNA expression level of HMGB1 in these samples, FastStart Universal SYBR Green Master (Rox; cat no. 04913914001; Roche Diagnostics, Indianapolis, IN, USA) was used, and qPCR was performed on a Roche Light Cycler 480 system. GAPDH was selected as the internal control. The primer sequences used for HMGB1 and GAPDH were as follows: HMGB1-Q forward (F), 5'-TATGGCAAAAGCGGACAAGG-3'; HMGB1-Q reverse (R), 5'-CTTCGCAACATCACCAATGGA-3'; GAPDH-QF, 5'-CTCTCTGCTCCTCCTGTTCGAC-3'; GAPDH-QR, 5'-TGAGCGATGTGGCTCGGCT-3'.

The $20 \mu \mathrm{l}$ total volume final reaction mixture consisted of: $1 \mu \mathrm{mol} / \mathrm{l}$ for each primer, $10 \mu \mathrm{l}$ Master Mix (Applied Biosystems; Thermo Fisher Scientific, Inc.) and $2 \mu \mathrm{l}$ cDNA. The negative control experiments were performed using distilled $\mathrm{H}_{2} \mathrm{O}$ as template. The $2^{-\Delta \Delta \mathrm{Ct}}$ algorithm was used to calculate the mRNA expression levels in tissues with different genotypes [24].

Western blot. Total protein was obtained from HCC tissues with different genotypes, and approximately $80 \mu \mathrm{g}$ of it was separated on a $10 \%$ polyacrylamide gel followed by transferring to a polyvinylidene difluoride membrane (cat no. IPVH00010, $0.45 \mu \mathrm{m}$, Millipore) and probed with primary antibodies against HMGB1 (cat no. ab77302, 1:10000, Abcam) and glyceraldehydes 3-phosphate dehydrogenase (cat no. ABAB-M-M001, 1:500, Good HERE Biotech Inc., Hangzhou China) and then secondary antibodies (1:1000, Beyotime Biotechnology). Enhanced chemiluminescence system was used to visualize the bands and the intensity of the bands.

Plasmid construction. A DNA fragment of $\sim 300 \mathrm{bp}$, including the del/del genotype of rs34000982 in the 3' UTR of $H M G B 1$ was directly synthesized by Genewiz Inc. (South Plainfield, NJ, USA) and cloned into Xba I and Fse 
III sites of a pGL3-control expression vector (Promega Corporation, Madison, WI, USA), named pGL3-HMGB1WT. A QuikChange Lightening Site-Directed Mutagenesis kit (cat. no. 210518, Stratagene; Agilent Technologies, Inc., CA, USA) was used to generate the mutant-type vector (pGL3-HMGB1-MT) including the ins/ins genotype of rs34000982. The sequence and direction of the resulting constructs (pGL3-HMGB1-WT and pGL3-HMGB1-MT) were verified by direct sequencing by Genewiz Inc.

In silico prediction of miRNAs binding with the 3' UTR of HMGB1 and disturbed by rs34000982. Mature human miRNA sequences were obtained from miRBase (http:// microrna.sanger.ac.uk) in 2016. The putative miRNAs could bind with the 3' UTR of HMGB1 and disturbed by rs34000982 was analyzed using miRanda (version 3.3a) software with default parameters as described previously [25].

Cell culture and luciferase reporter assay. Both Huh7 and HepG2 cell lines used in the present study were obtained from the Shanghai Cell Bank of the Chinese Academy of Sciences (Shanghai, China). Both cell lines were cultured in Dulbecco's modified Eagle's medium (cat no. 12491-015; Thermo Fisher Scientific, Inc.) supplemented with $10 \%$ fetal bovine serum (cat no. 10100147; Thermo Fisher Scientific, Inc.) and $1 \%$ penicillin-streptomycin at $37^{\circ} \mathrm{C}$ in a humidified chamber supplemented with $5 \%$ $\mathrm{CO}_{2}$. Cells were seeded in 24-well plates (cat. no. 3524; Corning Incorporated, Corning, NY, USA) at a density of $1 \times 10^{5}$ cells/well and transfected following culture at $37^{\circ} \mathrm{C}$ for $16 \mathrm{~h}$ using Lipofectamine 2000 (cat. no. 11668-019; Thermo Fisher Scientific, Inc.), according to the manufacturer's protocol. Subsequently, 500 ng pGL3-HMGB1-WT or pGL3-HMGB1-MT reconstructed vector and $50 \mathrm{ng}$ of pRL-SV40 (Promega Corporation) were co-transfected using Lipofectamine 2000 with 100 pmol miR-636 mimic or mimic control (Ambion; Thermo Fisher Scientific, Inc.) with $\sim 5 \times 10^{6}$ cells/well. Subsequent to $24 \mathrm{~h}$, cells were harvested immediately following addition of $100 \mu$ l passive lysis buffer (cat. no. E1910; Promega Corporation). Dualluciferase reporter assay (cat. no. E1910; Promega Corporation) was used to measure the firefly luciferase activity in cell lysates in a FilterMax F5, according to the manufacturer's protocol, and Renilla luciferase activity was used to normalize the data. All experiments were repeated at least 3 times with 6 replicates for each group.

Statistical analysis. The Hardy-Weinberg equilibrium was analyzed using the $\chi^{2}$ test for the genotype distribution in the control group. The association between rs34000982 and HCC risk was analyzed by logistic regression, adjusted for age (mean \pm standard deviation), gender, smoking, drinking, tumor stage and HBV infection status. A one-way analysis of variance followed by Dunnett's post-hoc test was used to compare the relative HMGB1 mRNA expression levels in HCC tissues between different genotypic groups. The difference in luciferase activity was examined using the Student's t-test. Statistical Analysis System software was used for all the statistical analyses (version 8.0; SAS Institute, Cary, NC, USA). A $\mathrm{p}<0.05$ was considered to indicate a statistically significant difference, and all statistical tests were two-sided.

\section{Results}

Association of rs34000982 with HCC susceptibility. Table 1 summarizes the demographic characteristics of the patients with HCC and the matched controls. The distribution of age, gender, smoking and drinking status was similar between the patients with HCC and the matched controls. The hepatitis B surface antigen-positive rate was $74.1 \%$ and $15.0 \%$ in the patients with HCC and the matched controls, respectively. Figure 1 presents the genotyping assays for rs34000982 and the sequencing results. The observed rs34000982 genotypic frequencies in the controls were consistent with the Hardy-Weinberg equilibrium ( $p>0.05)$. Table 2 indicates that the ins/ins genotype exhibited a significantly increased risk of HCC compared with the del/del genotype $[\mathrm{p}=0.001$; odds ratio $(\mathrm{OR})=2.43 ; 95 \%$ confidence interval (CI): 1.44-4.10]. In addition, the 4-bp insertion allele was associated with a $49 \%$ increased risk compared with the deletion allele $(\mathrm{p}=0.001 ; \mathrm{OR}=1.49 ; 95 \% \mathrm{CI}, 1.17-1.90)$. Collectively, these results suggest the association between rs34000982 and HCC susceptibility.

Association between rs34000982 genotype and HMGB1 mRNA expression levels. As demonstrated in Figure 2A, the HMGB1 mRNA level was higher in the insertion homozygous groups (ins/ins) than that of the heterozygous (ins/del) and

Table 1. Demographic characteristics of hepatocellular carcinoma cases and controls.

\begin{tabular}{lcc}
\hline Characteristics & $\begin{array}{c}\text { Patients, \% } \\
(\mathbf{n}=\mathbf{3 2 0})\end{array}$ & $\begin{array}{c}\text { Control, \% } \\
(\mathbf{n}=\mathbf{3 6 0})\end{array}$ \\
\hline Age (mean \pm S.D.) & $52.9 \pm 8.9$ & $54.1 \pm 9.7$ \\
Sex & & \\
$\quad$ Male & $208(65.0)$ & $238(66.1)$ \\
$\quad$ Female & $112(35.0)$ & $122(33.9)$ \\
Smoking status & & \\
$\quad$ Non-smokers & $210(65.6)$ & $242(67.2)$ \\
Former smokers & $52(16.3)$ & $60(16.7)$ \\
$\quad$ Current smokers & $58(18.1)$ & $58(16.1)$ \\
Drinking status & & $195(54.2)$ \\
$\quad$ Non-drinkers & $170(53.1)$ & $145(40.3)$ \\
Light drinkers & $130(40.6)$ & $20(5.5)$ \\
$\quad$ Heavy drinkers & $20(6.3)$ & \\
Tumor stages & & \\
Ia + Ib & $210(65.6)$ & \\
IIa + IIb & $80(25.0)$ & $54(15.0)$ \\
IIIa + IIIb & $30(9.4)$ & $306(85.0)$ \\
HBsAg & & \\
Positive & $237(74.1)$ & \\
Negative & $83(25.9)$ & \\
\hline
\end{tabular}

HBsAg, Hepatitis B surface antigen. 


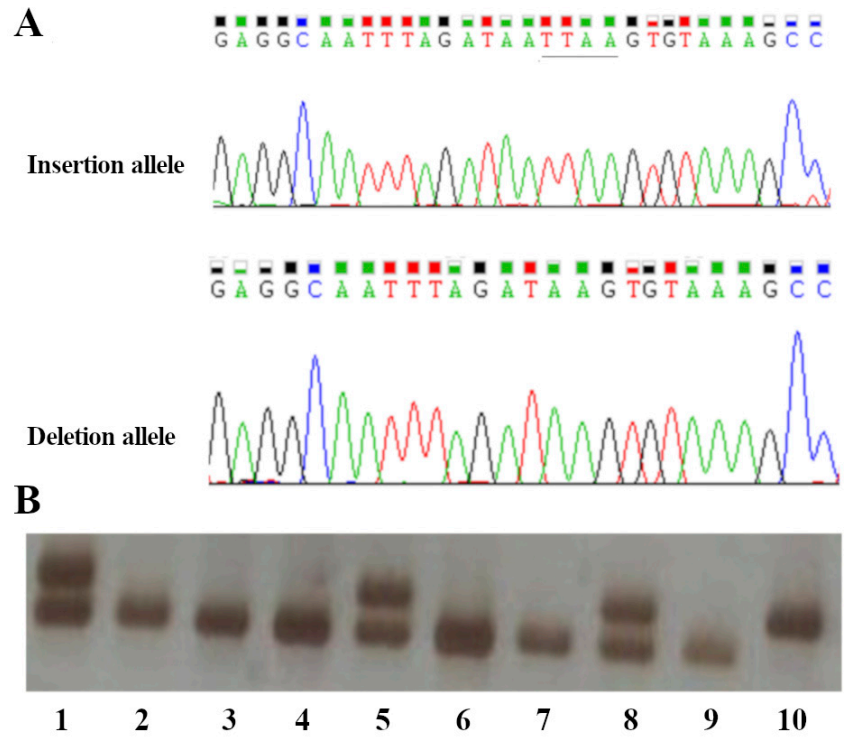

Figure 1. Sequencing and genotyping examples of rs34000982. A) Insertion and deletion allele sequences. The inserted 'TTAA' is underlined. B) Genotyping results using $7 \%$ non-denaturing PAGE and silver staining. Lanes 2, 3, 4, 6, 7 and $9 \mathrm{del} / \mathrm{del}$ genotype; lanes 1, 5, and 8 ins/del genotype; lanes 10 ins/ins genotype. Ins, insertion; del, deletion.

A

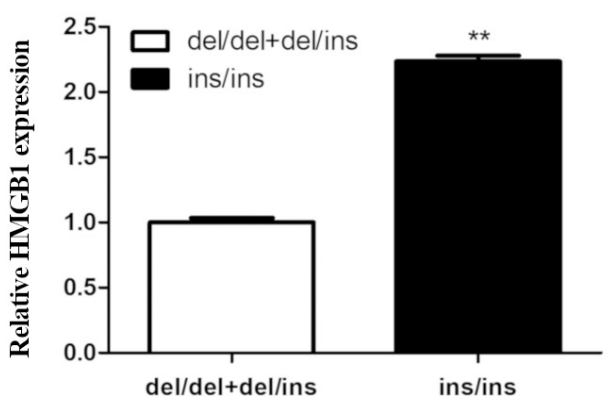

B

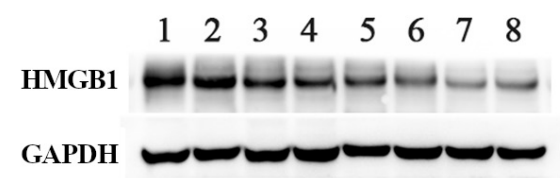

C

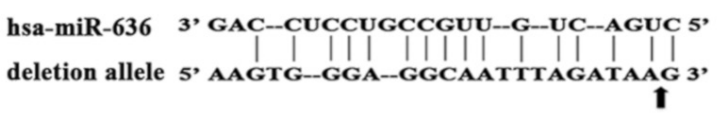

Figure 2. A) HMGB1 mRNA expression levels in HCC tissues with different genotypes. The HMGB1 mRNA expression level in HCC tissues with ins/ins genotype was $\mathbf{2 . 2 4}$ times that of the $\mathrm{del} / \mathrm{del}$ and ins/del genotype ${ }^{* *} \mathbf{p}<0.01$ vs. del/del+ ins/del). ins/ins, $n=7$, ins/del, $n=14$, del/del, $n=39$. B) HMGB1 protein expression levels in HCC tissues with different genotypes. The HMGB1 protein expression levels in HCC tissues with different genotypes. (Lanes 1 and 2 ins/ins genotype; Lanes 3, 4 and 5 ins/del genotype; Lanes 6, 7 and $8 \mathrm{del} / \mathrm{del}$ genotype. C) miRNA-HMGB1 mRNA binding model and position of the insertion allele (arrow). HMGB1, high mobility group box 1 ; miRNA, microRNA.
Table 2. Genotype distributions of the rs34000982 polymorphism in patients with HCC and healthy controls.

\begin{tabular}{lcccc}
\hline Genotype & $\begin{array}{c}\text { HCC (n=320) } \\
\mathbf{n}(\%)\end{array}$ & $\begin{array}{c}\text { Controls }(\mathbf{n}=360) \\
\mathbf{n}(\%)\end{array}$ & OR (95\% CI) & p-value \\
& $160(50.0)$ & $211(58.6)$ & 1 (reference) & \\
del/del & $112(35.0)$ & $123(34.2)$ & $1.20(0.86-1.68)$ & 0.28 \\
ins/del & $48(15.0)$ & $26(7.2)$ & $2.43(1.44-4.10)$ & 0.001 \\
ins/ins & $432(67.5)$ & $545(75.7)$ & 1 (reference) & \\
del allele & $208(32.5)$ & $175(24.3)$ & $1.49(1.17-1.90)$ & 0.001 \\
ins allele & & &
\end{tabular}

Ins, insertion; del, deletion; HCC, hepatocellular carcinoma; OR, odds ratio; $\mathrm{CI}$, confidence interval; ${ }^{\mathrm{A} A d j u s t e d}$ for age, gender, smoking status, drinking status, tumor stage and HBV infection.

deletion homozygous group (del/del). The average HMGB1 mRNA expression level of the insertion homozygous group was 2.24 times that of the heterozygous and deletion homozygous group. The data of this part in the present study suggested an association between genotypes and $H M G B 1$ mRNA expression levels in vivo.

Association between rs34000982 genotype and HMGB1 protein expression levels. As demonstrated in Figure 2B, the HMGB1 protein level was the highest in the HCC tissues with insertion homozygous (ins/ins) and then the heterozygous (ins/del) and deletion homozygous (del/del). The data of this part of the study suggested an association between genotypes and HMGB1 protein expression levels in vivo.

rs34000982 polymorphism affects HMGB1 transcription activity by regulating its binding with miR-636 in vitro. The bioinformatics analysis indicated that rs34000982 lies within the predicted human miR-636 binding site, and the insertion allele of rs34000982 may disrupt the binding of miR-636 with the 3' UTR of HMGB1 (Figure 2C). To assess this prediction, two vectors, pGL3-HMGB1-WT (with del/del genotype) and pGL3-HMGB1-MT (with ins/ins genotype) were constructed. In the pGL3-HMGB1-MT group, the expression level of HMGB1 mRNA, indicated by firefly luciferase activity, in the miR-636 mimic-transfected group was similar to that of the mimic control group. However, for the pGL3-HMGB1WT group, the expression of HMGB1 mRNA in the miR-636 mimic transfected group was significantly lower in the mimic control group (Figure 3). These results suggest that miR-636 may bind with the 3' UTR of $H M G B 1$ with del/del wild genotype and negatively regulate $H M G B 1$ transcription, and that the insertion allele may weaken its regulatory effect by disrupting the binding of miR-636 to the 3' UTR of HMGB1. Therefore, the in vitro experiments suggest that the polymorphism rs34000982 affects $H M G B 1$ expression by altering the binding of miR-636 to the 3' UTR of HMGB1.

\section{Discussion}

In the present study we set out to examine the association between polymorphisms in the 3' UTR of HMGB1 and HCC susceptibility. Through extensive analyses we found that the 
A

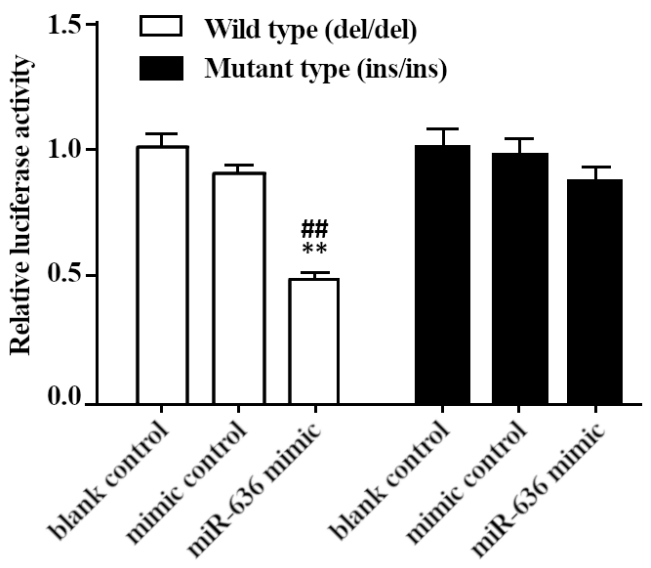

Huh7
B

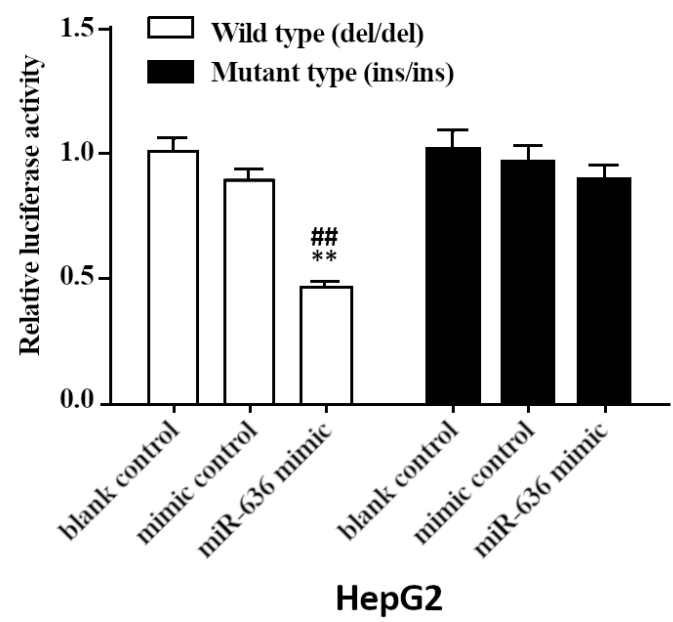

Figure 3. HMGB1 transcriptional activity affected by rs34000982 and determined by luciferase reporter assay. The changes of the relative luciferase activity of Huh7 and HepG2 cells that were co-transfected with miR-636 mimic or mimic control and pGL3-HMGB1-WT or pGL3- HMGB1-MT vectors. The pGL3-HMGB1-WT and miR-636 mimic transfected group exhibited a significantly lower luciferase activity than the mimic control transfected group $\left({ }^{* *} \mathbf{p}<0.01 ;{ }^{\# *} \mathbf{p}<\mathbf{0 . 0 1}\right)$. The Renilla luciferase vector was selected as an internal control. ${ }^{* *}$ represents the difference between the blank control group and the miR-636 mimic group in the pGL3-HMGB1-WT transfected group is significant, and ${ }^{\# \#}$ represents the difference between the miR-636 mimic group transfected with pGL3-HMGB1-WT and pGL3- HMGB1-MT is significant.

ins/ins genotype of rs34000982 in the 3' UTR of HMGB1 was significantly associated with an increased risk of HCC. The following phenotype-genotype association experiment indicated that the expression level of $H M G B 1$ at both mRNA and protein level was the highest in the HCC tissues with insertion homozygous (ins/ins), followed by the heterozygous (ins/del) and deletion homozygous (del/del). In addition, the luciferase reporter assay suggested that the ins/ins genotype potentially worked in full, or at least partially, by disturbing the binding of miR-636 with the 3' UTR of HMGB1 to regulate $H M G B 1$ expression. To the best of our knowledge, this is the first study to investigate the association between the indel polymorphism in the HMGB1 3'UTR and the risk of HCC, and the potential mechanism involved.

HMGB1, discovered as a non-histone chromosomal protein in 1973, is one of the HMGB family members (HMGB $1,2,3$ and 4) with a molecular weight of 25 to $30 \mathrm{kDa}$ [26]. Serum HMGB1 levels are increased in patients with HCC and the expression of HMGB1 in the liver closely correlates with proliferation, invasion, pathological grade, distant metastases, and drug resistance of liver cancer [27-32]. In addition, HMGB1 released from the hypoxic tumor microenvironment can bind to TLR4 and RAGE, which in turn mediate HCC invasion and metastasis by activating inflammasome, NF- $\kappa \mathrm{B}$, and AKT pathways [8, 12, 17, 33, 34]. Moreover, therapeutic targeting of HMGB1 inhibits HMGB1 expression, release, and activity, which in turn suppresses tumor growth in liver metastasis models of colon cancer [8, 35-37]. These findings suggest that HMGB1 plays a critical role in the pathogenesis and treatment of HCC. All of these data are consistent with our results that the risk insertion allele with a high level of $H M G B 1$ mRNA and protein expression level may increase the risk of HCC development.

As described above, abnormal expression of HMGB1 participates in the progression of HCC, and a number of previous studies have indicated that polymorphisms in the 3' UTR of genes disturb their binding with miRNAs or reveal novel binding sites for miRNAs $[38,39]$. This affects the expression level of target genes and may be involved in numerous types of diseases, including cancer [39, 40]. Gao et al. found that an indel polymorphism at a miRNA-122binding site in the 3' UTR of interleukin (IL)-1a conferred increased risk for HCC [38], and Wang et al. demonstrated that rs56288038 in the 3' UTR of interferon regulatory factor 1 (IRF-1) regulated by miR-502-5p promoted the development of gastric cancer [39]. Certain previous studies have also indicated that single nucleotide polymorphisms or indels in miRNA binding sites of their target genes may participate in the development or progression, or be associated with fluorouracil resistance of HCC by affecting the binding of miRNAs with the target genes $[40,41]$. To explore the possible mechanism through which rs34000982 is involved in HCC susceptibility, miRNAs that can bind with the 3' UTR of HMGB1 and be affected by rs34000982 were predicted, and it was identified that the ins/ins genotype could disturb the bind of miR-636 with the 3' UTR of HMGB1, and consequently up-regulated the expression of $H M G B 1$, thus increasing the risk of HCC.

In 2013, Jang and colleagues firstly reported that miR-636 might function as a tumor suppressor miRNA through the 
ANT2/miR-636/Ras axis in HCC [42]. The roles miRNAs in cancer are dependent on their target genes, and the results of the present study are consistent with the previous study on HCC that miR-636 serves as a tumor suppressor miRNA through targeting HMGB1. Due to the complicated mechanism of HCC development, additional functional analyses are required.

The present study contained multiple limitations: The subjects in the study were all ethic Han, and the numbers were limited, so additional large-scale studies in different populations are required. An additional limitation is that the possible mechanism of action of the indel was predicted by software, further experimental validation is required.

In summary, the present study demonstrated that the rs34000982 polymorphism in the 3' UTR of HMGB1 may contribute to HCC susceptibility, possibly working in full, or at least partially, through an effect on HMGB1 transcriptional activity, by disturbing its binding with miR-636.

Acknowledgements: We gratefully acknowledge the participation of patients with HCC and cancer-free individuals. The present study was supported by the Science and Technology Development Project of Healthy and Family Planning Commission of Changshu (grant no. csws201705) and the Suzhou Science and Technology Development Project (grant no. SYS201652).

\section{References}

[1] BRAY F, FERLAY J, SOERJOMATARAM I, SIEGEL RL, TORRE LA et al. Global cancer statistics 2018: GLOBOCAN estimates of incidence and mortality worldwide for 36 cancers in 185 countries. CA Cancer J Clin 2018; 68: 394-424. https://doi.org/10.3322/caac.21492

[2] MCGLYNN KA, PETRICK JL, LONDON WT. Liver cancer, pp. 635-660. In. M Thun, MS Linet, JR Cerhan, CA Haiman, D Schottenfeld (Eds.). Cancer Epidemiology and Prevention. $4^{\text {th }}$ Edition. New York: Oxford University Press 2018; p 1328. ISBN 9780190238667

[3] CHEN CJ, CHEN DS. Interaction of hepatitis B virus, chemical carcinogen, and genetic susceptibility: multistage hepatocarcinogenesis with multifactorial etiology. Hepatology 2002; 36: 1046-1049. https://doi.org/10.1053/Jhep.2002.37084

[4] ARAVALLI RN, STEER CJ, CRESSMAN EN. Molecular mechanisms of hepatocellular carcinoma. Hepatology 2008; 48: 2047-2063. https://doi.org/10.1002/Hep.22580

[5] MOSEVITSKY MI, NOVITSKAYA VA, IOGANNSEN MG, ZABEZHINSKY MA. Tissue specificity of nucleo-cytoplasmic distribution of HMG1 and HMG2 proteins and their probable functions. Eur J Biochem 1989; 185: 303-310. https://doi.org/10.1111/j.1432-1033.1989.tb15116.x

[6] BUSTIN M, LEHN DA, LANDSMAN D. Structural features of the HMG chromosomal proteins and their genes. Biochim Biophys Acta 1990; 1049: 231-243. https://doi. org/10.1016/0167-4781(90)90092-G
[7] CALOGERO S, GRASSI F, AGUZZI A, VOIGTLANDER T, FERRIER P et al. The lack of chromosomal protein Hmg1 does not disrupt cell growth but causes lethal hypoglycaemia in newborn mice. Nat Genet 1999; 22: 276-280. https://doi. org/10.1038/10338

[8] CHENG P, DAI W, WANG F, LU J, SHEN M et al. Ethyl pyruvate inhibits proliferation and induces apoptosis of hepatocellular carcinoma via regulation of the HMGB1-RAGE and AKT pathways. Biochem Biophys Res Commun 2014; 443: 1162-1168. https://doi.org/10.1016/j.bbrc.2013.12.064

[9] KOHLES N, NAGEL D, JUNGST D, STIEBER P, HOLDENRIEDER S. Predictive value of immunogenic cell death biomarkers HMGB1, sRAGE, and DNase in liver cancer patients receiving transarterial chemoembolization therapy. Tumour Biol 2012; 33: 2401-2409. https://doi.org/10.1007/ s13277-012-0504-2

[10] ZHOU TB. Role of high mobility group box 1 and its signaling pathways in renal diseases. J Recept Signal Transduct Res 2014; 34: 348-350. https://doi.org/10.3109/10799893.2014.9 04875

[11] ROH YS, SEKI E. Toll-like receptors in alcoholic liver disease, non-alcoholic steatohepatitis and carcinogenesis. J Gastroenterol Hepatol 2013; 28 Suppl 1: 38-42. https://doi. org/10.1111/jgh.12019

[12] YAN W, CHANG Y, LIANG X, CARDINAL JS, HUANG H et al. High-mobility group box 1 activates caspase- 1 and promotes hepatocellular carcinoma invasiveness and metastases. Hepatology 2012; 55: 1863-1875. https://doi.org/10.1002/ hep. 25572

[13] CONTI L, LANZARDO S, ARIGONI M, ANTONAZZO R, RADAELLI E et al. The noninflammatory role of high mobility group box 1/Toll-like receptor 2 axis in the self-renewal of mammary cancer stem cells. FASEB J 2013; 27: 4731-4744. https://doi.org/10.1096/fj.13-230201

[14] STOETZER OJ, FERSCHING DM, SALAT C, STEINKOHL O, GABKA CJ, et al. Circulating immunogenic cell death biomarkers HMGB1 and RAGE in breast cancer patients during neoadjuvant chemotherapy. Tumour Biol 2013; 34: 81-90. https://doi.org/10.1007/s13277-012-0513-1

[15] FAHMUELLER YN, NAGEL D, HOFFMANN RT, TATSCH $\mathrm{K}$, JAKOBS $\mathrm{T}$ et al. Immunogenic cell death biomarkers HMGB1, RAGE, and DNAse indicate response to radioembolization therapy and prognosis in colorectal cancer patients. Int J Cancer 2013; 132: 2349-2358. https://doi. org/10.1002/ijc.27894

[16] SUREN D, YILDIRIM M, DEMIRPENCE O, KAYA V, ALIKANOGLU AS et al. The role of high mobility group box 1 (HMGB1) in colorectal cancer. Med Sci Monit 2014; 20: 530-537. https://doi.org/10.12659/MSM.890531

[17] KOSTOVA N, ZLATEVA S, UGRINOVA I, PASHEVA E. The expression of HMGB1 protein and its receptor RAGE in human malignant tumors. Mol Cell Biochem 2010; 337: 251-258. https://doi.org/10.1007/s11010-009-0305-0

[18] MULLER S, RONFANI L, BIANCHI ME. Regulated expression and subcellular localization of HMGB1, a chromatin protein with a cytokine function. J Intern Med 2004; 255: 332-343. https://doi.org/10.1111/j.1365-2796.2003.01296.x 
[19] ZHOU C, YU Q, CHEN L, WANG J, ZHENG S et al. A miR-1231 binding site polymorphism in the 3' UTR of IFNAR1 is associated with hepatocellular carcinoma susceptibility. Gene 2012; 507: 95-98. https://doi.org/10.1016/j. gene.2012.06.073

[20] JIN Y Q, YU Q, ZHOU D Y, CHEN L, HUANG X et al. The Mitochondrial DNA 9-bp Deletion Polymorphism Is a Risk Factor for Hepatocellular Carcinoma in the Chinese Population. Genet Test Mol Biomarkers 2012; 16: 330-334. https:// doi.org/10.1089/gtmb.2011.0208

[21] YU Q, ZHOU CX, CHEN NS, ZHENG SD, SHEN LM et al. A polymorphism within ErbB4 is associated with risk for hepatocellular carcinoma in Chinese population. World J Gastroenterol 2012; 18: 383-387. https://doi.org/10.3748/wjg. v18.i4.383

[22] EDGE SB, COMPTON CC. The American Joint Committee on Cancer: the 7th edition of the AJCC cancer staging manual and the future of TNM. Ann Surg Oncol 2010; 17: 1471-1474. https://doi.org/10.1245/s10434-010-0985-4

[23] ALLEN RC, GRAVES G, BUDOWLE B. Polymerase chain reaction amplification products separated on rehydratable polyacrylamide gels and stained with silver. Biotechniques 1989; 7: 736-744.

[24] LIVAK KJ, SCHMITTGEN TD. Analysis of relative gene expression data using real-time quantitative PCR and the 2(-Delta Delta C(T)) Method. Methods 2001; 25: 402-408. https://doi.org/10.1006/meth.2001.1262

[25] JOHN B, ENRIGHT AJ, ARAVIN A, TUSCHL T, SANDER C et al. Human MicroRNA targets. PLoS Biol 2004; 2: e363. https://doi.org/10.1371/journal.pbio.0020363

[26] BIANCHI ME, MANFREDI AA. High-mobility group box 1 (hmgb1) protein at the crossroads between innate and adaptive immunity. Immunol Rev. 2007; 220: 35-46. https://doi. org/10.1111/j.1600-065X.2007.00574.x

[27] TAKADA M, KU Y, TOYAMA H, SUZUKI Y, KURODA Y. Suppressive effects of tea polyphenol and conformational changes with receptor for advanced glycation end products (RAGE) expression in human hepatoma cells. Hepatogastroenterology 2002; 49: 928-931.

[28] DONG YD, CUI L, PENG CH, CHENG DF, HAN BS et al. Expression and clinical significance of HMGB1 in human liver cancer: Knockdown inhibits tumor growth and metastasis in vitro and in vivo. Oncol Rep 2013; 29: 87-94. https:// doi.org/10.3892/or.2012.2070

[29] JIANG W, WANG Z, LI X, FAN X, DUAN Y. High-mobility group box 1 is associated with clinicopathologic features in patients with hepatocellular carcinoma. Pathol Oncol Res 2012; 18: 293-298. https://doi.org/10.1007/s12253-0119442-3

[30] KAWAHARA N, TANAKA T, YOKOMIZO A, NANRI H, ONO $\mathrm{M}$ et al. Enhanced coexpression of thioredoxin and high mobility group protein 1 genes in human hepatocellular carcinoma and the possible association with decreased sensitivity to cisplatin. Cancer Res 1996; 56: 5330-5333.
[31] LIU F, ZHANG Y, PENG Z, GAO H, XU L et al. High expression of high mobility group box 1 (hmgb1) predicts poor prognosis for hepatocellular carcinoma after curative hepatectomy. J Transl Med 2012; 10: 135. https://doi. org/10.1186/1479-5876-10-135

[32] XIAO J, DING Y, HUANG J, LI Q, LIU Y et al. The association of HMGB1 gene with the prognosis of HCC. PLoS One 2014; 9: e89097. https://doi.org/10.1371/journal.pone.0089097

[33] CHEN RC, YI PP, ZHOU RR, XIAO MF, HUANG ZB et al. The role of HMGB1-RAGE axis in migration and invasion of hepatocellular carcinoma cell lines. Mol Cell Biochem 2014; 390: 271-280. https://doi.org/10.1007/s11010-014-1978-6

[34] YASER AM, HUANG Y, ZHOU RR, HU GS, XIAO MF et al. The Role of receptor for Advanced Glycation End Products (RAGE) in the proliferation of hepatocellular carcinoma. Int J Mol Sci 2012; 13: 5982-5997. https://doi.org/10.3390/ ijms 13055982

[35] CHENG P, NI Z, DAI X, WANG B, DING W et al. The novel BH-3 mimetic apogossypolone induces Beclin-1- and ROS-mediated autophagy in human hepatocellular cells. Cell Death Dis 2013; 4: e489. https://doi.org/10.1038/cddis.2013.17

[36] JIANG W, WANG Z, LI X, LI J, HUANG Y et al. Reduced high-mobility group box 1 expression induced by RNA interference inhibits the bioactivity of hepatocellular carcinoma cell line HCCLM3. Dig Dis Sci 2012; 57: 92-98. https:// doi.org/10.1007/s10620-011-1944-Z

[37] LIANG X, CHAVEZ AR, SCHAPIRO NE, LOUGHRAN P, THORNE SH et al. Ethyl pyruvate administration inhibits hepatic tumor growth. J Leukoc Biol 2009; 86: 599-607. https://doi.org/10.1189/jlb.0908578

[38] GAO Y, HE Y, DING J, WU K, HU B et al. An insertion/deletion polymorphism at miRNA-122-binding site in the interleukin-1alpha 3' untranslated region confers risk for hepatocellular carcinoma. Carcinogenesis 2009; 30: 2064-2069. https://doi.org/10.1093/carcin/bgp283

[39] WANG B, YANG H, SHEN L, WANG J, PU W et al. Rs56288038 (C/G) in 3'UTR of IRF-1 Regulated by MiR-502$5 p$ Promotes Gastric Cancer Development. Cell Physiol Biochem 2016; 40: 391-399. https://doi.org/10.1159/000452554

[40] FAN Y, QIAN X, ZHANG C. U/G SNP rs111904020 in 3'UTR of STAT3 regulated by miR-214 promotes hepatocellular carcinoma development in Chinese population. Tumour Biol 2016; 37: 14629-14635. https://doi.org/10.1007/ s13277-016-5352-Z

[41] WANG C, ZHAO H, ZHAO X, WAN J, WANG D et al. Association between an insertion/deletion polymorphism within 3'UTR of SGSM3 and risk of hepatocellular carcinoma. Tumour Biol 2014; 35: 295-301. https://doi.org/10.1007/ s13277-013-1039-x

[42] JANG JY, LEE YS, JEON YK, LEE K, JANG JJ et al. ANT2 suppression by shRNA restores miR-636 expression, thereby downregulating Ras and inhibiting tumorigenesis of hepatocellular carcinoma. Exp Mol Med 2013; 45: e3. https://doi. org/10.1038/emm.2013.1 